This is a postprint version of the following published document:

Greenberg, J. \& Méndez, E. (2007). Introduction: Toward a More Library-Like Web via Semantic Knitting. Cataloging \& Classification Quarterly, 43 (3-4), pp. 1-8.

DOI: $10.1300 / J 104 v 43 n 03 \_a$

(C) Taylor \& Francis, 2007 


\title{
Introduction: Toward a More Library-Like Web via Semantic Knitting
}

\author{
Jane Greenberg \\ Eva Méndez
}

Over the last five years, the library community's attention to the Semantic Web has progressed at a creeping pace. More recently-within the last year-the Semantic Web appears to be gaining greater attention by information professionals looking for answers to manage the complex world of the Web. This development is perhaps best explained by Paul Miller's (2005; 2006) stimulating and thought provoking notion of "Library 2.0" inspired, in part, by Tim O'Reilly's (2005) highly influential "What Is Web 2.0." Part of Miller's central thesis is that the rich untapped structured data sources which libraries possess need to be exposed and mined. He believes the 21 st century library is obligated to expose its rich data and provide a new level of service, information access, and knowledge discovery for the good of its users and citizens at large. Miller's Library 2.0 integrates with the foundation ideas and evolution of the Semantic Web, and invites librarians to think outside the box and actively engage in the development of the Semantic Web. This special volume demonstrates that librarians and other information professionals, including people involved in information intensive work (e.g., medical doctors), are taking Miller's advice and building a more library-like World Wide Web (Web) through what we call "semantic knitting." 


\section{THE SEMANTIC WEB AND UNDERLYING PRINCIPLES}

The Semantic Web represents Berners-Lee's initial idea of the Web, and is defined as "an extension of the current Web in which information is given well-defined meaning, better enabling computers and people to work in cooperation" (Berners-Lee et al., 2001). In more conventional terms, Connolly (1998) explains that the Semantic Web will relieve him from the "bane of my [his] existence" of performing mundane tasks that he knows a computer can perform for him (e.g., searching for a doctor who accepts his health insurance plan).

The Semantic Web requires that information bearing entities on the Web be tagged with machine-processable meaning (semantic metadata) in a standard way. The standardization will enable the exchange, use, and reuse of information. Tagging entities with ontological or other standard values will result in a semantically knitted network that can support computational activities and provide people with services efficiently. A fundamental component to this activity is the development, registration, and sharing of metadata schemas and ontologies.

Koivunen and Miller (2001) identify the following principles to guide Semantic Web development:

1. Everything can be identified by URIs (Uniform Resource Identifier). People, places, things, and attributes about these entities can all be identified with an URI.

2. Resources and links have types. Identifying relationships such as "is version of," "has subject," and "is author" make data machine processable.

3. Partial information is tolerated. There is no limit on the encoding of entities (resource, links, and relationships).

4. There is no need for absolute truth. Truth of information on the Web cannot be guaranteed, but Semantic Web agents will be able to determine what information is trustworthy via context.

5. Evolution is supported. The Semantic Web is organic, and new information can be added to older information.

6. Minimalist design. The goal is to standardize no more than is necessary; "When we use the Semantic Web technologies the result should offer much more possibilities than the sum of the parts."

Although these principles emphasize the simplicity of the Semantic Web, they are only valuable if there is a means by which they can be achieved. Concrete examples demonstrating these principles are needed 
to motivate Semantic Web development. This volume contributes to this need by presenting Semantic Web foundations, projects, and philosophical ideas.

\section{STATUS OF THE SEMANTIC WEB}

We teach in the area of organizing information and digital content and data management. We encourage students to read about the Semantic Web, explore Semantic Web developments, and think critically about the Semantic Web's future. At times we are challenged when discussing the Semantic Web, particularly when students and colleagues ask: "Where is it [The Semantic Web]?" "Can I see the Semantic Web in operation?" and "What about privacy issues?" Our replies to such questions generally unfold in the following order: Semantic Web development is underway with enabling technologies and standards, such as the Resource Description Framework (RDF), Web Ontology Language (OWL), Friend Of A Friend (FOAF), and the newest language Simple Knowledge Organizations System (SKOS). We also point to RSS (RDF Site Summary/Really Simple Syndication), which incorporates RDF and has had a global impact on the Web-based news syndications. These technologies provide the technical backbone required to form the Semantic Web's infrastructure. These technologies have also motivated the development of Semantic Web tools and projects (Table 1) helping to form an infrastructure that allows information to be digested and used in new ways as envisioned by Berners-Lee.

Notwithstanding Semantic Web progress (e.g., Table 1), it would be incorrect to say that these developments support a mature Semantic Web. In other words, when asked if the Semantic Web currently supports agents scheduling personal appointments or planning a vacation to Hawaii, we reply "no." We can, however, look at online calendaring applications and travel services, such as Expedia.com, and see semantic components that could be harvested for Semantic Web development. Despite these developments, current Semantic Web limitations have led to criticism (Marshall, 2004; Shirky, 2003). Criticism is useful for addressing current shortcomings and planning the next step in developing a Semantic Web. The downside of criticisms is that they often fail to note where important progress has been made.

What is important and stands as evidence of major progress is the wide range of communities with a growing interest in information standards, data interoperability, and open information. Never in our time 
TABLE 1. Examples of Semantic Web Tools and Projects

\begin{tabular}{|c|c|}
\hline Semantic Web Tools & Semantic Web Projects \\
\hline $\begin{array}{l}\text { Annotea: http://www.w3.org/2001/Annotea } \\
\text { Annozilla: http://annozilla.mozdev.org/ } \\
\text { FOAF RDF vocabulary: } \\
\text { http://xmlns.com/foaf/0.1/ } \\
\text { ORACLE: } \\
\text { http://www.oracle.com/technology/tech/semantic_ } \\
\text { technologies/index.html } \\
\text { RDFPic: http://jigsaw.w3.org/rdfpic/ } \\
\text { Swoogle: http://swoogle.umbc.edu/ } \\
\text { Tabulator (SW Browser): } \\
\text { http://dig.csail.mit.edu/2005/ajar/ajaw/tab.html } \\
\text { http://widgets.opera.com/widget/5053 }\end{array}$ & $\begin{array}{l}\text { APAIS (Australian Public Affairs Information } \\
\text { Service) Thesaurus: } \\
\text { http://www.nla.gov.au/apais/thesaurus/ } \\
\text { Biocomplexity Thesaurus of the National } \\
\text { Biological Information Infrastructure: } \\
\text { http://thesaurus.nbii.gov/portal/server.pt } \\
\text { FAO Thesaurus: } \\
\text { http://www.fao.org/aims/ag_intro.htm } \\
\text { MusicBrainz: http://musicbrainz.org/ } \\
\text { NCI Thesaurus: } \\
\text { http://www.mindswap.org/2003/CancerOntology/ } \\
\text { Physnet: http://www.physnet.de/PhysNet/ } \\
\text { Semantic Web Environmental Directory: } \\
\text { http://www.swed.org.uk/swed/index.html }\end{array}$ \\
\hline
\end{tabular}

has there been a more universal interest in producing structured, standardized information. The idea of the Semantic Web initiative will, at the very least, help many more initiatives to benefit from standardized organization and access to information. We conclude then, that the Semantic Web is being knitted. We may not create one big knitted snug blanket, although the number of Semantic Web projects is growing, and they can be knitted together via standards for more powerful computing operations than previously possible.

\section{PURPOSE OF THIS VOLUME}

The overall purpose of this special volume is to explore the Semantic Web initiative. More specifically, the goals are to:

- Bring together a series of articles by leaders in library and information science, computer science, and information intensive domains, who are exploring the Semantic Web and playing a significant role in its development.

- Provide librarians and other readers with a greater understanding of the Semantic Web.

- Aid librarians/information professionals is discovering the role they may play developing, growing, and maintaining the Semantic Web. 
Library science is a cross-domain discipline that has always involved experts from a variety of disciplines (e.g., library science, computer science, and people with topical subject expertise). One reason for this is that libraries can be found with collection holdings documenting any discipline. Another related reason is that a library can be found serving nearly any type of client. The Semantic Web needs librarians and informational professionals not only because of their experience and expertise with standards and bibliographic control, but their experience and expertise as information custodians for the last several hundred years (Greenberg, 2006). In short, we have edited this special volume because we firmly believe that librarians can play a significant role in developing the Semantic Web.

\section{WHY KNITTING THE SEMANTIC WEB?}

We have chosen to present the articles in this volume in the context knitting for the following reasons:

- Knitting means to interlock or join closely. Garments and fabrics are produced by interlocking single strands of yarn, broken bones heal through knitting, and a close-knit relationship is generally a supportive and positive relationship. A knitted Semantic Web will result in a more powerful and robust Web.

- Several monographs published about the Semantic Web draw upon tasks relating to the craft of knitting. For example, there was first "weaving" the Web (Berners-Lee, 1999), followed by "creating" (Hjelm, 2001), and "spinning" (Fensel, 2003).

- A simple "knit-purl" stitch (knitting) is used to create simple to quite complex and sophisticated designs. Similarly, simple semantics underlying the Semantic Web intend to support simple to complex and sophisticated operations.

- Knitting permeates many strata-from the men who knit on Taquile Island, Lake Titicaca, Peru, and knitting cooperatives all over the world (Greenberg, 1996), to recent faddish "knit-ins"1 and knitting celebrities. ${ }^{2}$ The Semantic Web is applicable to all citizens.

\section{FRAMEWORK FOR THIS VOLUME}

Knitting the Semantic Web is arranged into two parts. Part I addresses Semantic Web foundations, standards, and tools; and Part II presents Semantic Web projects and perspectives. 
Part I begins with a foundation article by Campbell discussing how Foucault's The Birth of the Clinic serves as a pattern for understanding the paradigm shifts represented by the Semantic Web. This work is followed by McCathieNevile and Méndez's work on RDF, its expressive power, and its ability to underlie the new Library catalog card of the 21 st century. Harper and Tillett then explore Library of Congress controlled vocabularies and their value and application for developing the Semantic Web. Next, Miles and Pérez-Agüera introduce the newest Semantic Web language, Simple Knowledge Organization System (SKOS), which is for representing controlled structured vocabularies, including thesauri, classification schemes, subject heading systems, and taxonomies. This work is followed by Tennis' presentation of a conceptual framework and a methodology for managing scheme versioning in the Semantic Web. Part I concludes with Rogers' review of semantic tools and technologies that libraries and other knowledge-intensive organizations can use for building Semantic Web projects.

Part II of this volume begins with an article by Severiens and Thiemann presenting their RDF triples database, Physnet, a Semantic Web portal service for physics. This article is followed by Michon's article on the value of Semantic Web technologies in biomedicine and his work, which is grounded in RDF. Michon, a medical doctor, also identifies several important roles that library and information scientists can play in developing a more powerful biomedical information infrastructure in the context of the Semantic Web. Next is an article by Liang, Salokhe, Sini, and Keizer presenting the intellectual processes and technical specifications for developing the United Nations, Food and Agriculture's ontology. This work is followed by a piece by Graves, Constabaris, and Brickley introducing the Semantic Web's Friend Of A Friend (FOAF) vocabulary specification, and also presenting a real world case study of FOAF for solving specific identity management problems in an information technology department at a University. Greenberg then presents a deductive analysis on the applicability of primary library functions (collection development, cataloging, reference, and circulation) to Semantic Web development. The last article is a perspective piece by Stuart Weibel, founder of the Dublin Core Metadata Initiative, one of the most significant programs bringing together members of the library and Semantic Web communities. In this concluding article, Weibel provides a personal perspective on libraries and the Semantic Web in the context of social bibliography. 


\section{CONCLUSION}

Librarians have the intellectual knowledge and skills required to work with Semantic Web enabling technologies (e.g., XML, RDF). We do not need to be computer programmers to do this, as there are many tools available to aid our use of these standards (see the Rogers contribution). What is important is that we are experts in developing information standards, and, most importantly we have the most sophisticated skills and experience in knowledge representation. In sum, if librarians transfer their skills to the semantic knitting required for a Semantic Web, we can help build a better Web.

\section{ACKNOWLEDGEMENTS}

The Editors would like to acknowledge all of the authors for their contributions to this volume. The Editors would also like to thank Sandy Roe, Teri Devoe, and the $C C Q$ 's Editorial Board for their support of this special volume. The Editors would also like to thank the Fulbright Program for support that allowed Eva Méndez to work as EU Research Scholar at the SILS Metadata Research Center, University of North Carolina at Chapel Hill, over the last year to complete this book.

\section{NOTES}

1. The Big Knit In: http://www.knitin.co.uk/; Anglicare Knit-in 2006: http://www. abc.net.au/perth/knitin/default.htm.

2. Celebrity Knitters . . L Look Who's Knitting: http://www.worldknit.com/celebrityknitters. html.

\section{REFERENCES}

Berners-Lee, T. (1999). Weaving the Web: The Original Design and Ultimate Destiny of the World Wide Web by Its Inventor. San Francisco: Harper.

Berners-Lee, T., Hendler, J., and Lassila, O. (2001). The Semantic Web. Scientific American, 284(5): 34-43. Also available at: http://www.sciam.com/article.cfm? articleID=00048144-10D2-1C70-84A9809EC588EF21.

Connolly, D. (1998). The XML Revolution. World Wide Web Consortium: http:// www.w3.org/People/Connolly/9810xn.html.

Fensel, D., Wahlster, W., Lieberman, H., and Hendler, J. (Eds.) (2003). Spinning the Semantic Web: Bringing the World Wide Web to Its Full Potential. Cambridge: MIT Press, 2003. 
Greenberg, J. (2006). Advancing Semantic Web via Library Functions. Cataloging \& Classification Quarterly. 43(3/4): 203-225.

Greenberg, M. (1996). Bolivia: Women's Knitting Cooperative. South American Explorer Issue, 45: 8-15.

Hjelm, J. (2001). Creating the Semantic Web with RDF: Professional Developer's Guide. New York: John Wiley \& Sons.

Koivunen, M., and Miller E. (2001). W3C Semantic Web Activity. E. Hyvönen (Ed.). Semantic Web Kick-Off in Finland: Vision, Technologies, Research, and Applications. Helsinki Institute for Information Technology (HIIT), Helsinki, Finland. May 19, 2002, pp. 27-43. Also available online at: http://www.cs.helsinki.fi/u/eahyvone/ stes/semanticweb/kick-off/proceedings.pdf, and http://www.w3.org/2001/12/semwebfin/w3 csw.

Marshall, C. (2004). Taking a Stand on the Semantic Web. Texas: Center for the Study of Digital Libraries: http://www.csdl.tamu.edu/ marshall/mc-semantic-web.html.

Miller, P. (2005). Web 2.0: Building the New Library. Ariadne, 45: http://www. ariadne.ac.uk/issue 45/miller.

Miller, P. (2006). Coming Together around Library 2.0: A Focus for Discussion and a Call to Arms. D-Lib Magazine, 12(4): http://www.dlib.org/dlib/april06/miller/04miller. html.

O'Reilly, T. (2005). What Is Web 2.0: Design Patterns and Business Models for the Next Generation of Software. O'ReillyNet: http://www.oreillynet.com/pub/a/oreilly/ tim/news/2005/09/30/what-is-web-20.html.

Shirky, C. (2003). The Semantic Web, Syllogism, and Worldview. [First published on the Networks, Economics, and Culture mailing list.]: http://www.shirky.com/ writings/semantic_syllogism.html. 